\title{
Surgical management of primary and secondary pilocytic astrocytoma of the cerebellopontine angle (in adults and children) and review of the literature
}

\author{
Sasan Darius Adib ${ }^{1}$ (D) Martin U. Schuhmann ${ }^{1} \cdot$ Johann-Martin Hempel ${ }^{2} \cdot$ Antje Bornemann $^{3}$. \\ Rocio Evangelista Zamora ${ }^{1} \cdot$ Marcos Tatagiba $^{1}$
}

Received: 4 January 2020 / Revised: 3 March 2020 / Accepted: 27 March 2020 / Published online: 15 April 2020

(C) The Author(s) 2020

\begin{abstract}
Glial tumors in the cerebellopontine angle (CPA) are uncommon and comprise less than 1\% of CPA tumors. We present four cases of pilocytic astrocytoma of the CPA (PA-CPA) that were treated in our department. Patients who received surgical treatment for PA-CPA from January 2004 to December 2019 were identified by a computer search of their files from the Department of Neurosurgery, Tübingen. Patients were evaluated for initial symptoms, pre- and postoperative facial nerve function and cochlear function, complications, and recurrence rate by reviewing surgical reports, patient documents, neuroradiological data, and follow-up data. We identified four patients with PA-CPA out of about 1500 CPA lesions $(\sim 0.2 \%)$, which were surgically treated in our department in the last 16 years. Of the four patients, three were male, and one was a female patient. Two were adults, and two were children (mean age 35 years). A gross total resection was achieved in three cases, and a subtotal resection was attained in one case. Two patients experienced a moderate facial palsy immediately after surgery (House-Brackmann grade III). In all cases, the facial function was intact or good (House-Brackmann grades I-II) at the long-term follow-up (mean follow-up 4.5 years). No mortality occurred during follow-up. Three of the patients had no recurrence at the latest follow-up (mean latest follow-up 4.5 years), while one patient had a slight recurrence. PA-CPA can be safely removed, and most complications immediately after surgery resolve in the long-term follow-up.
\end{abstract}

Keywords Cerebellopontine angle $\cdot$ CPA $\cdot$ Pilocytic astrocytoma $\cdot$ Glioma $\cdot$ Brainstem $\cdot$ Facial nerve

Sasan Darius Adib

sasan_adib2002@yahoo.de

Martin U. Schuhmann

martin.schuhmann@med.uni-tuebingen.de

Johann-Martin Hempel

johann-martin.hempel@med.uni-tuebingen.de

Antje Bornemann

antje.bornemann@med.uni-tuebingen.de

Rocio Evangelista Zamora

rocio.evangelista@med.uni-tuebingen.de

Marcos Tatagiba

marcos.tatagiba@med.uni-tuebingen.de

1 Department of Neurosurgery, University of Tuebingen, Hoppe-Seyler-Str. 3, 72076 Tuebingen, Germany

2 Department of Neuroradiology, University of Tuebingen, Hoppe-Seyler-Str. 3, 72076 Tuebingen, Germany

3 Department of Neuropathology, University of Tuebingen, Hoppe-Seyler-Str. 3, 72076 Tuebingen, Germany

\section{Introduction}

Pilocytic astrocytomas (PA) comprise 6\% of all intracranial tumors and are the most (in some studies the second most [30]) common primary brain tumors in children. Over 40\% [9] of PA are localized in the cerebellum, followed by supratentorial locations (35\%) [9]. Other typical locations are the optic pathway and hypothalamus [30] (11\%) [9], the brainstem (9\%) [9], and the spinal cord.

Pilocytic astrocytomas of the cerebellopontine angle (PA$\mathrm{CPA}$ ) are rare [30] and might grow as primary PA (which have their origin in the root entry zone of cranial nerves in the CPA) $[2,16]$ or as exophytic brainstem or cerebellar PA with secondary invasion of the CPA $[2,16]$. They may mimic other tumors such as vestibular schwannoma [37, 40, 48].

PA-CPA are a formidable challenge from neurosurgical perspective, and different strategies are necessary to protect surrounding neurovascular structures. 
The goal of this retrospective study is to analyze the surgical management of exophytic PA of the brainstem with invasion of the CPA, especially with focus on the clinical presentation, surgical strategy, the extent of resection, and early and late treatment outcomes.

\section{Materials and methods}

\section{Data collection and inclusion criteria}

Patients who had undergone surgery for PA-CPA from January 2004 to December 2019 were identified through a computer search of the patients' medical files at our neurosurgery department. Four patients with PA-CPA of > 1500 CPA lesions $(0.2 \%)$ had undergone surgery in our department. The patients were evaluated for presenting symptoms, preoperative and postoperative facial nerve function (according to the House and Brackmann scale), cochlear function (according to the Gardner-Robertson scale), extent of resection, recurrence rate, survival rates, and complications by reviewing patient documents, surgical reports, neuroradiological data, and follow-up data. Furthermore, the surgical strategy was analyzed. PA-CPA had been confirmed histopathologically in each case.

The study was approved by the ethics committee.

\section{Surgical technique and strategies}

Three patients had been positioned under general anesthesia in supine position and one in semisitting position according to our standards. The anesthesiologic setup in the case of semisitting position included transesophageal echocardiography for early detection of air emboli. All patients underwent a retrosigmoid craniectomy. Intraoperative monitoring included motor evoked potentials (MEP) and electromyography (EMG) recordings of the facial nerve and the lower cranial nerves, and auditory evoked potentials and MEP and sensory evoked potentials of the upper and lower extremities.

\section{Follow-up}

Clinical examination for facial nerve (according to the House and Brackmann scale) and hearing function (according to the Gardner-Robertson scale) was performed in all cases 3 days after surgery and was repeated at the 3-month follow-up. Postoperative MRI-examinations were performed 3 months after surgery. Further follow-up examinations have been performed every 6 months for at least 1 year.

\section{Results}

Four patients (three were male, and one was female) with PACPA were included in this study. Two were adults (ages 53 years and 71 years), and two were children (ages 7 years and 10 years). Three PA-CPA were located on the right side, and one was on the left side.

\section{Radiological findings}

Three patients had secondary PA-CPA arising from the cerebellum (1/4) and the cerebellar peduncle (2/4), and one patient had a primary PA-CPA (with arising from the root entry zone of the VIII cranial nerve). MRI exams showed cystic PA-CPA in two cases (Fig. 1a left and 1b left) and non-cystic PA-CPA in two cases (Fig. 1c left and 1d left). In the two cystic PACPA cases, the MRI revealed brainstem compression with displacement and secondary hydrocephalus. One of the noncystic PA-CPA cases also showed moderate brainstem compression (Fig. 1c left). Both patients with cystic PA-CPA were children (mean age 8.5 years), whereas both patients with noncystic PA-CPA were adults (mean age 62 years) (Table 1 ). The pediatric PA-CPA presented typically with a cystic cerebellar mass with enhancing mural nodule (Fig. 1a left and 1b left). Contrary, adult PA-CPA were atypical: both showed only solid tumor components (Fig. 1c left and 1d left). One adult PACPA showed no contrast enhancement (Fig. 1d left).

\section{Presenting symptoms}

Case 1: This 7-year-old male presented with slight facial palsy (H+B grade II), nausea, vomiting, and nystagmus for 2 months.

Case 2: This 10-year-old female with a history of dyspnea for 2 years presented in our outpatient ambulance with slight facial palsy $(\mathrm{H}+\mathrm{B}$ grade II), disturbance in walking, nausea, vomiting, and mild hemiparesis for 1 month.

Case 3: This 71-year-old male presented with disturbance in walking, urinary incontinence, and slight dementia for many months.

Case 4: This 53-year-old male with a history of a testicular carcinoma, which had been treated by surgery and chemotherapy, presented with disturbance in coordination and sensitivity of the left arm for 10 days.

All presenting symptoms were related to the compression of the brainstem or cranial nerves, or to hydrocephalus.

The most common symptoms were facial palsy (2/4) on the side of the PA-CPA (H+B II), disturbance in walking $(2 / 4)$ [one of them was due to the compression of the brainstem, and one of them was due to hydrocephalus, including urinary 
Fig. 1 a Left (case 1), b left (case 2), c left (case 3), d left (case 4): Preoperative axial contrastenhanced T1-weighted magnetic resonance imaging scans of each patient with PA-CPA (A+B: pediatric PA-CPA presented typically with a cystic cerebellar mass with enhancing mural nodule; $\mathrm{C}+$ D: adult PA-CPA presented atypically with only solid tumor components). a Middle, $\mathbf{b}$ middle, $\mathbf{c}$ middle, $\mathbf{d}$ middle: Postoperative axial contrast-enhanced T1weighted magnetic resonance imaging scans; a gross total resection (GTR) of the PA-CPA was achieved in three cases (3/4). In one case, only a subtotal removal of the tumor was performed (blue block arrow). a Right, b right, c right, d right: Postoperative axial T2-weighted magnetic resonance images; anatomical facial nerve preservation was achieved during surgery in all cases (red block arrows)

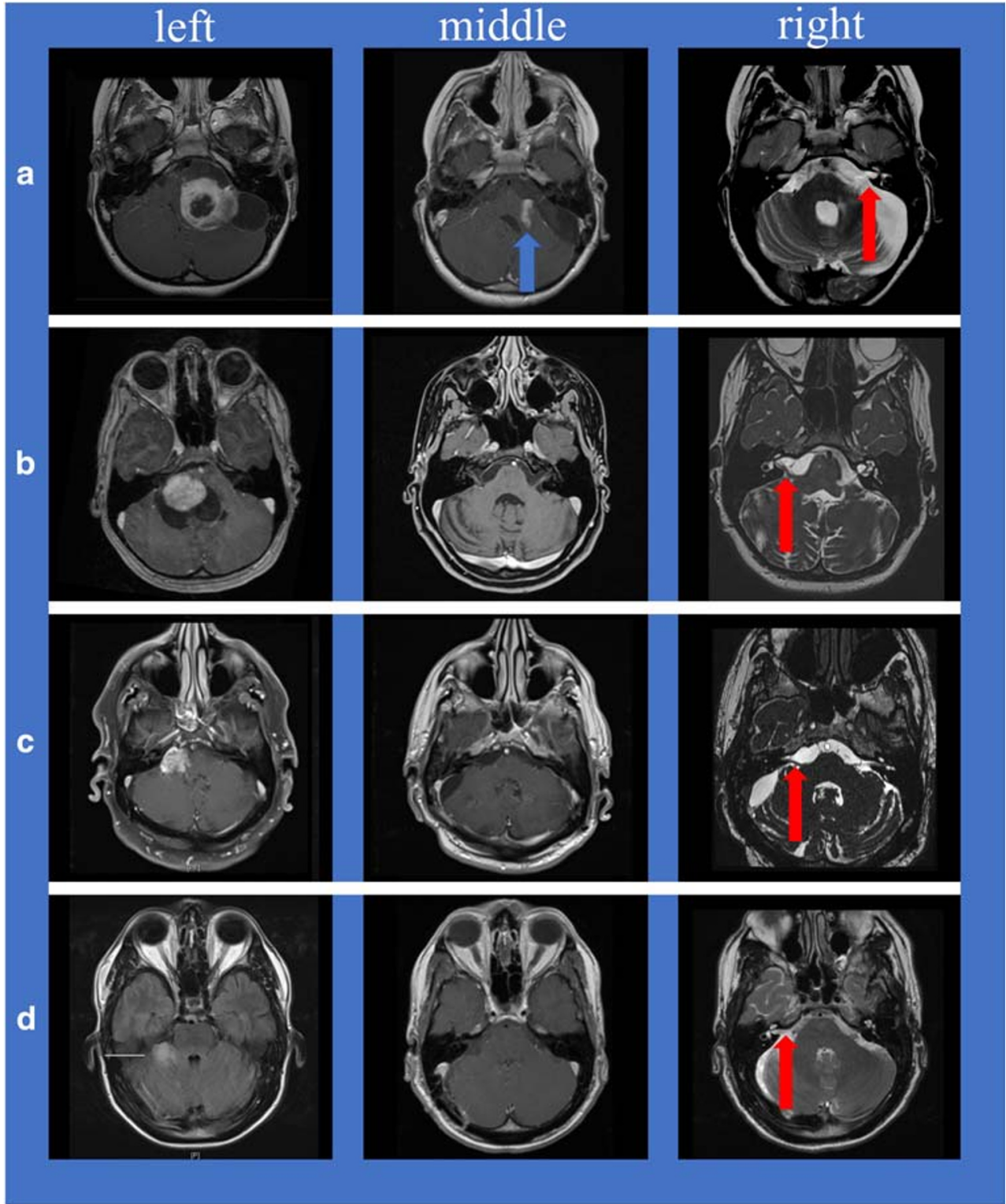

incontinence (1/4) and slight dementia (1/4)], and vomiting and nausea $(2 / 4)$.

Other symptoms included slight hemiparesis (1/4), disturbance of coordination and sensitivity of the left arm (1/4), dyspnea (1/4), and nystagmus (1/4).

\section{Tumor resection strategy}

1. Cystic and non-cystic PA-CPA:

In case of large cystic PA-CPA (Fig. 1a left and 1b left) a decompression of the cyst should be in most cases the first step (Fig. 2a). The cystic wall should be removed (Fig. 2b), but only in case that it is not too adherent to surrounding structures. After removal of the cyst, the surface of the solid tumor portion was incised (Fig. 2c) and a debulking (using an ultrasonic aspirator) was performed (Fig. 2d). After debulking, the tumor was dissected from surrounding structures.

2. Primary and secondary PA-CPA:

In the case of primary PA-CPA (with arising from the root entry zone of the vestibular nerve), the vestibular nerve had to be sacrificed. In secondary PA-CPA, the extent of resection depends on the infiltration of the brainstem, cerebellar peduncle, and cerebellum (see below). 
Table 1 Histopathological and radiological findings and further oncological therapy

\begin{tabular}{|c|c|c|c|c|c|c|c|}
\hline & $\begin{array}{l}\text { Age/ } \\
\text { sex }\end{array}$ & $\begin{array}{l}\text { Histopathological } \\
\text { confirmed }\end{array}$ & $\begin{array}{l}\text { Cystic } \\
\text { component }\end{array}$ & $\begin{array}{l}\text { Brainstem } \\
\text { compression }\end{array}$ & $\begin{array}{l}\text { Extent of } \\
\text { resection }\end{array}$ & Recurrence & $\begin{array}{l}\text { Further oncological } \\
\text { therapy }\end{array}$ \\
\hline 1 & $7 / \mathrm{m}$ & Yes & Yes & Yes & Subtotal & Slight progression & No \\
\hline 2 & $10 / f$ & Yes & Yes & Yes & Total & No & No \\
\hline 3 & $71 / \mathrm{m}$ & Yes & No & $\begin{array}{l}\text { Yes } \\
\text { (moderate) }\end{array}$ & Total & No & No \\
\hline 4 & $53 / \mathrm{m}$ & Yes & No & No & Total & No & No \\
\hline
\end{tabular}

\section{Extent of resection and recurrence rate}

A gross total resection (GTR) of the PA-CPA was achieved in three cases (3/4) (Table 1) (Fig. 1b middle, 1c middle, and 1d middle). In one patient (case 1), only a subtotal removal of the tumor was performed (Fig. 1a middle) to preserve the facial nerve function and because of infiltration of the cerebellar peduncle (Fig. 1a left and 1a middle).

Three of the patients had no recurrence at the latest followup (mean latest follow-up of all patients 4.5 years) (Table 1). Pediatric patient with incomplete resection of PA-CPA demonstrated slight progression of residual tumor tissue 1 year after resection. In the further follow-up, no further progression was observed.

\section{Histopathological results}

PA was histologically confirmed in each case (Table 1) with typical characteristics of low cellularity, presence of Rosenthal fibers, eosinophilic granular bodies, and a biphasic consistency with microcystic and compact areas.

\section{Further therapies}

None of the patients received radiotherapy or chemotherapy before or after surgery (Table 1). One patient had a VP shunt inserted during a second procedure due to the remaining hydrocephalus (case 3).

\section{Facial nerve function}

Anatomical facial nerve preservation was achieved in all four patients (Fig. 1a right, $1 \mathrm{~b}$ right, $1 \mathrm{c}$ right, and $1 \mathrm{~d}$ right). Before surgery, two patients (case 1 and 2) had a slight facial palsy (H+B grade II) (Table 2). Immediately after surgery, two patients (case 1 and case 3 ) had a moderate facial palsy (H+B grade III), and one (case 2) had a slight facial palsy (H+B grade II) (Table 2).

In two of the four cases, no functional impairment of the facial nerve $(\mathrm{H}+\mathrm{B}$ grade $\mathrm{I})$ was detectable at the 3-month follow-up examination. In the two other cases (cases 1 and 3 ), there was a slight palsy of the facial nerve $(\mathrm{H}+\mathrm{B}$ grade $\mathrm{II})$ at the 3-month follow-up and long-term follow-up (Table 2).
Fig. 2 Different steps of tumor resection strategy: in case of large cystic component, a decompression of the cyst should be performed (a) and, furthermore, if possible, a removal of the cyst wall (b). After removal of the cyst, the surface of the solid tumor portion was incised (c) and a debulking was performed (d)

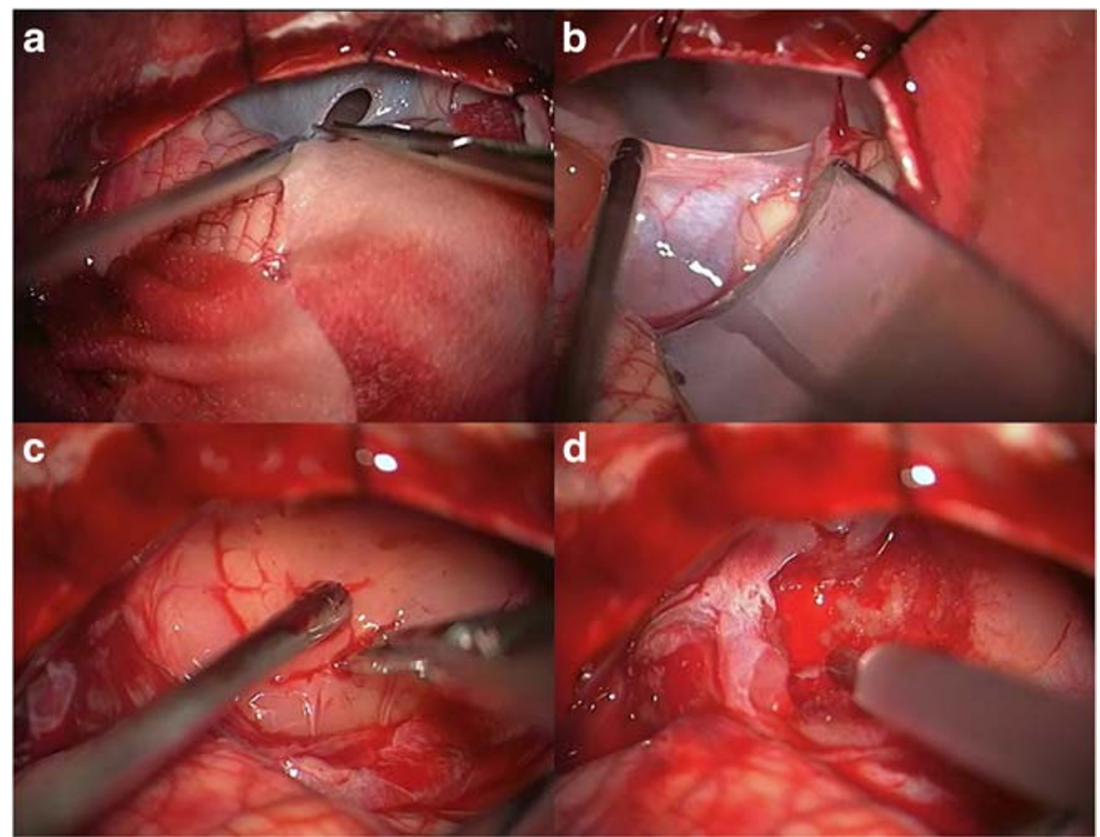


Table 2 Preoperative and postoperative facial $(\mathrm{H}+\mathrm{B}=$ House-Brackmann grade $)$ and cochlear function

\begin{tabular}{llllllll}
\hline $\begin{array}{l}\text { Age/ } \\
\text { sex }\end{array}$ & $\begin{array}{l}\text { Extent of } \\
\text { resection }\end{array}$ & $\begin{array}{l}\text { Preoperative facial } \\
\text { function }(\mathrm{H}+\mathrm{B})\end{array}$ & $\begin{array}{l}\text { Facial function immediately } \\
\text { after surgery }(\mathrm{H}+\mathrm{B})\end{array}$ & $\begin{array}{l}\text { Facial function in } \\
\text { long term }(\mathrm{H}+\mathrm{B})\end{array}$ & $\begin{array}{l}\text { Preoperative } \\
\text { cochlear function }\end{array}$ & $\begin{array}{l}\text { Postoperative } \\
\text { cochlear function }\end{array}$ \\
\hline 1 & $7 / \mathrm{m}$ & Subtotal & II & III & II & No hearing impairment & Surditas on one side \\
2 & $10 / \mathrm{f}$ & Total & II & II & II & No hearing impairment & No hearing impairment \\
3 & $71 / \mathrm{m}$ & Total & I & III & I & No hearing impairment & Surditas on one side \\
4 & $53 / \mathrm{m}$ & Total & I & I & No hearing impairment & No hearing impairment \\
\hline
\end{tabular}

\section{Cochlear nerve function}

None of the patients had a cochlear dysfunction (GR grade I) before surgery (Table 2). Anatomical cochlear nerve preservation was achieved in three patients (all patients except the one with primary PA-CPA arising from VIII cranial nerve). Two patients (one with primary and one with secondary PA-CPA) had hearing loss (GR grade V) after surgery on the side of surgery (case 1 and case 3) (Table 2).

\section{Complications}

Further complications (besides facial and cochlear nerve dysfunction) immediately after surgery included palsy of the VI (1/4) and XII (1/4) cranial nerves (case 2), dysphagia (1/4) (case 3), and hemiparesis (2/4) (in case 1 a new hemiparesis and in case 2 worsening of a previously known hemiparesis). All these symptoms recovered in the long term, except for a slight remnant hemiparesis in one case (case 2). No mortality occurred during follow-up.

\section{Discussion}

Most common lesions in the CPA are vestibular schwannoma (70-80\%) [4], meningioma (10-15\%) [4], followed by epidermoid cysts (5\%) [4]. The remaining percentage includes a variety of different lesions $[4,5]$.

CPA gliomas are rare $[2,16]$ and can be classified into primary and secondary CPA gliomas $[2,16]$.

\section{Primary CPA glioma}

Primary CPA glioma arises from the root entry zone (either the glial segment or the transition zone) of the cranial nerves in the CPA $[2,16]$. Cranial nerves comprise three distinct histologically segments: the glial segment, a transition zone, and a peripheral segment $[2,16]$.

The glial segment is histologically identical in structure to the central nervous system (the nerve axons are supported by neuroglia: astrocytes and oligodendrocytes), while the peripheral segment structure is similar to a peripheral nerve (nerve fibers are insulated by Schwann cells) [2, 16].
Between glial and peripheral segments lies a transitional or intermediate zone. Various studies analyzed the differences in length of different segments in different cranial nerves [8, 39, 41].

In 1904, Panse [32] was the first who described a case of a fibrillary astrocytoma of the VIII cranial nerve root entry zone, and Cushing [12] described a second case in 1917.

Arnautovic et al. were the first who reported a case of glioma from the proximal portion of the trigeminal nerve. Arnautovic et al. [2] concluded that most cases reported in the literature had been either fibrillary or gemistocytic astrocytomas $[2,3,6,15,20,21,25]$. Primary PA-CPA had been described by Francesco et al. [16] (a case of trigeminal nerve root entry zone PA) and Beutler et al. [3] (a case of VIII cranial nerve root entry zone PA). The first pediatric primary pilocytic astrocytoma had been reported by Mirone et al. [30].

In addition, malignant primary CPA gliomas had also been described so far. Breshears et al. [7] and Kasliwal et al. [23] described a case of a primary glioblastoma multiforme (GBM) of the trigeminal nerve root entry zone and primary GBM of the oculomotor nerve [34, 45], and the VIII cranial nerve [47] had also been reported.

Arnautovic [2] concluded that the longest glial segment is found in cranial nerve VIII and that this explained the predominance of cranial nerve VIII [22] as the origin of CPA glioma, followed by the sensory part of cranial nerve $\mathrm{V}$, and then the facial and glossopharyngeal nerves.

\section{Secondary CPA glioma}

Secondary CPA gliomas are exophytic tumors arising from the brainstem or the cerebellum with a secondary invasion of the CPA [16].

Choux et al. [11] described four different types of brainstem gliomas (type 1: diffuse brainstem gliomas; type 2 (solid or cystic): focal intrinsic tumors; type 3: exophytic tumors; type 4: cervicomedullary tumors).

Brainstem gliomas may show complex growth patterns [13] and typically rarely grow exophytically into the CPA [48].

In 1947, Revilla [35] published a series by Walter Dandy, who had operated on CPA tumors, and found 12 cases of gliomas of the CPA. Five cases were astrocytoma (but were 
not more precisely classified). In their study, Famer et al. [14] described brainstem gliomas of the pons with exophytic lateral growth (CPA glioma).

PA are typically intraparenchymal in origin and are rarely exophytic [2]. In the case of exophytic growth, they usually grow dorsally to the brainstem [26] and will largely fill the fourth ventricle [26], usually with little or no detectable infiltration of the brainstem.

In addition, other gliomas of the CPA (except PA) have been described in the literature. Non-pilocytic glioma of the CPA (NPG-CPA) included among other things anaplastic astrocytoma [24] and GBM $[1,29]$.

Matsuda et al. [29] summarized four cases [27, 46] (including their case) of exophytic GBM of the cerebellum with secondary invasion in the CPA, and also other authors [1, $10,36]$ published cases of GBM of the CPA, in some cases even with secondary invasion of the cranial nerves by GBM $[28,33]$.

Other cases of CPA glioma, which are not more precisely classified, are described by Gentry et al. [17] (seven cases of CPA glioma out of 75 cases of CPA tumors) and Ozawa [31] (exophytic pontine glioma).

\section{PA-CPA glioma in children and adults}

Guillamo et al. [19] concluded in their study, "adult brainstem gliomas are different from the childhood subtypes." In adults, brainstem gliomas are, among other things, less aggressive than in children [19] (survival is significant shorter in children than in adults) [38]. They furthermore summarized that brainstem gliomas in adults are poorly understood because they are rarer in adults than they are in children [19].

Selvapandian et al. [38] concluded that the mean duration of symptoms before admission is significantly shorter in children (3.6 months in children versus 9.7 months in adults), while there was no significant difference in the clinical features. While the tumor grade seems to be a significant factor regarding the survival in adults, it seems not to be in children [38].

Exophytic gliomas account for $10-15 \%$ of brainstem gliomas in children [42].

Probably the largest series in the literature of PA-CPA had been published by Tomita and Grahovac [44], who analyzed CPA tumors in infants and children and found in a series of 44 CPA tumors, 11 were PA-CPA.

Tomita and Grahovac [44] discovered that from 12 benign secondary CPA glioma (11 PA and one ganglioglioma), 6 arise from the restiform body, two from the medulla oblongata, two from the pons, one from brachium pontis, and one from the cerebellum. However, they did not separate between the cerebellopontine angle and the cerebellomedullary fissure and included both of them in their study. Therefore, it is expected that some of the lesions are not strictly defined as CPA glioma.

In their series [44], 52\% presented with hydrocephalus, while in the series of CPA lesions in children by Zuccaro and Sosa [49], 33\% of patients presented with hydrocephalus. In our study, two of four patients had hydrocephalus.

Additional symptoms (gait ataxia, cranial nerve dysfunction, and facial weakness) were similar to our study.

One interesting finding in our study was that both patients with cystic PA-CPA were much younger when compared with both patients with solid PA-CPA (mean age 8.5 years versus 62 years).

Similar to Guillamo et al. [19] results, the differences in the mean ages and radiological findings suggest that these might be different subtypes of the disease.

In the series by Guillamo et al. [19] of 48 adult brainstem gliomas, 12 showed exophytic growth (10 prepontine and two posterior). However, the study included a very heterogeneous pathological spectrum (with only one PA), and the lateral growth in the CPA was not described.

To the best of our knowledge, the largest single institutional series of adult PA was published by Theeler et al. [43] (127 patients). They showed that the majority of adult PA are supratentorial [43]. The brainstem was involved in $24 \%$ of cases, and the cerebellum in $13 \%$ of cases [43].

\section{Surgical strategy}

Even today, with new technical possibilities, surgery of pilocytic astrocytoma-cerebellopontine angle (PA-CPA) presents a formidable challenge. In 2004, Yousry et al. [48] demonstrated that specialized magnetic resonance imaging sequences (3D CISS and 3D MP-Rage) provided the surgeon preoperatively with important information for planning surgical management, such as the relationship between a tumor and adjacent neural structures (cranial nerves and brainstem) and the borders of the tumor within the cisterns.

In our opinion, also intraoperative monitoring (MEP and EMG recordings of the facial nerve and lower cranial nerves, and auditory evoked potentials, MEPs, and sensory evoked potentials of the upper and lower extremities) during surgery is of high importance and helps the surgeon to preserve cranial nerve functions.

Furthermore, it is essential to recognize that the surgical strategy in cystic and non-cystic PA-CPA is different. In the case of large cystic PA-CPA, a decompression of the cyst should be, in most cases, the first step (similar to the strategy described by Francesco et al. [16]) and the cystic wall should be removed when it is not too adherent to surrounding structures. After this step, the surface of the solid tumor portion should be incised, and debulking should be performed. The last step is to dissect the tumor from the surrounding structures. Arnautovic et al. concluded that usually in the case of 
PA-CPA, a clear arachnoid cleavage plane is found between the tumor and the surrounding tissue [2].

In the case of primary PA-CPA, there is a further important decision: Should one sacrifice or preserve the cranial nerve from which the tumor arose? In our study, we decided to sacrifice it, because the loss of cranial nerve VIII function on one side is compensable. Most authors, with similar cases of PA-CPA of cranial nerve VIII, made the same decision [3, 30, 45]. The decision would be more complicated in the case of the PA originating from cranial nerve VII. In such a case, partial resection or gross total removal with facial nerve anastomosis using a sural nerve graft should be discussed.

In a case of secondary PA-CPA, the extent of resection depends on the infiltration of the brainstem, the cerebellar peduncle, and the cerebellum.

In our study, three CPA gliomas were totally removed, and one CPA glioma was subtotally removed. At the same time, the facial nerve was anatomically preserved in all cases and showed good functional outcome in all cases in the long term. The patient with the incomplete resection of the PA-CPA demonstrated a slight progression of residual tumor tissue 1 year after the resection. On further follow-up, no further progression was observed.

In a case of clear further progression or recurrence, a future second surgery, radiotherapy, or chemotherapy should be discussed, in our opinion (according to our tumor board).

Similar to our results, most authors concluded that, in cases of exophytic brain stem gliomas, a gross total or subtotal removal with a favorable prognosis is possible in most patients [18].

Regarding the clinical outcome and complications, it is difficult to find clear analyses in the literature. While primary PA-CPA are only described in single case reports, secondary PA-CPA are only described as part of other gliomas of CPA or PA of other locations (usually, most studies did not separate PA-CPA from PA of the brainstem, but especially for the clinical outcome, this is an essential difference).

The series by Walter Dandy [35] focused on the differential diagnosis of gliomas of the CPA from other lesions of the CPA. However, no outcome is mentioned, and only astrocytomas of CPA (without any more precisely histopathological classification) are described.

Farmer et al. [14] focused on brainstem gliomas in common, but one group concentrated on brainstem gliomas of the pons with exophytic lateral growth (CPA glioma). They concluded [14] that in cases of non-diffuse brainstem tumors, 1994 marked a pivotal year in their treatment. While before $1994,75 \%$ of patients received biopsy, but in the time after 1994 , only $15 \%$ received biopsy, as radical surgery became the treatment of choice.

To best of our knowledge, there is no study about PA-CPA in literature.

\section{Limitations}

The main limitation of this study is the small number of patients, due to the rare prevalence of PA-CPA.

In summary, CPA gliomas can be classified into primary and secondary CPA gliomas depending on their site of origin.

Two different subtypes of PA-CPA exist: (1) cystic PACPA in young patients and (2) non-cystic PA-CPA in older patients.

A PA-CPA can be safely removed, and most complications that occur immediately after surgery have resolved in the longterm follow-up. Nevertheless, the treatment of such a rare tumor remains a challenge.

Funding information Open Access funding provided by Projekt DEAL.

\section{Compliance with ethical standards}

Conflict of interest The authors declare that they have no conflicts of interest.

Ethical approval All procedures performed in studies involving human participants were in accordance with the ethical standards of the institutional and/or national research committee (ethics committee of the University Hospital Tübingen, Germany; reference number 280/ 2017BO2) and with the 1964 Helsinki declaration and its later amendments or comparable ethical standards.

Informed consent For this type of study (retrospective design, anonymized data), formal consent was not required.

Open Access This article is licensed under a Creative Commons Attribution 4.0 International License, which permits use, sharing, adaptation, distribution and reproduction in any medium or format, as long as you give appropriate credit to the original author(s) and the source, provide a link to the Creative Commons licence, and indicate if changes were made. The images or other third party material in this article are included in the article's Creative Commons licence, unless indicated otherwise in a credit line to the material. If material is not included in the article's Creative Commons licence and your intended use is not permitted by statutory regulation or exceeds the permitted use, you will need to obtain permission directly from the copyright holder. To view a copy of this licence, visit http://creativecommons.org/licenses/by/4.0/.

\section{References}

1. Ahn MS, Jackler RK (1997) Exophytic brain tumors mimicking primary lesions of the cerebellopontine angle. Laryngoscope 107: 466-471. https://doi.org/10.1097/00005537-199704000-00008

2. Arnautovic KI, Husain MM, Linskey ME (2000) Cranial nerve root entry zone primary cerebellopontine angle gliomas: a rare and poorly recognized subset of extraparenchymal tumors. J Neuro-Oncol 49:205-212. https://doi.org/10.1023/a:1006488905526

3. Beutler AS, Hsiang JK, Moorhouse DF, Hansen LA, Alksne JF (1995) Pilocytic astrocytoma presenting as an extra-axial tumor in the cerebellopontine angle: case report. Neurosurgery 37:125-128. https://doi.org/10.1227/00006123-199507000-00019 
4. Bonneville F, Savatovsky J, Chiras J (2007) Imaging of cerebellopontine angle lesions: an update. Part 1: enhancing extra-axial lesions. Eur Radiol 17:2472-2482. https://doi.org/10. 1007/s00330-007-0679-x

5. Bonneville F, Savatovsky J, Chiras J (2007) Imaging of cerebellopontine angle lesions: an update. Part 2: intra-axial lesions, skull base lesions that may invade the CPA region, and non-enhancing extra-axial lesions. Eur Radiol 17:2908-2920. https://doi.org/10.1007/s00330-007-0680-4

6. Brackmann DE, Bartels LJ (1980) Rare tumors of the cerebellopontine angle. Otolaryngol Head Neck Surg 88:555559. https://doi.org/10.1177/019459988008800508

7. Breshears JD, Ivan ME, Cotter JA, Bollen AW, Theodosopoulos PV, Berger MS (2015) Primary glioblastoma of the trigeminal nerve root entry zone: case report. J Neurosurg 122:78-81. https://doi.org/ 10.3171/2014.10.JNS14449

8. Bridger MW, Farkashidy J (1980) The distribution of neuroglia and Schwann cells in the 8th nerve of man. J Laryngol Otol 94:13531362. https://doi.org/10.1017/s0022215100090186

9. Burkhard C, Di Patre P-L, Schüler D, Schüler G, Yaşargil MG, Yonekawa Y, Lütolf UM, Kleihues P, Ohgaki H (2003) A population-based study of the incidence and survival rates in patients with pilocytic astrocytoma. J Neurosurg 98:1170-1174. https://doi.org/10.3171/jns.2003.98.6.1170

10. Chen F, Li Z, Weng C, Li P, Tu L, Chen L, Xie W, Li L (2017) Progressive multifocal exophytic pontine glioblastoma: a case report with literature review. Chin J Cancer 36:34. https://doi.org/10. 1186/s40880-017-0201-Z

11. Choux M (1999) Pediatric neurosurgery, 1. Publ. Churchill Livingstone, London

12. Cusing H (1917) Tumors of nervus acusticus and syndrome of the cerebellopontine angle. WB Saunders Co, Philadelphia

13. Epstein FJ, Farmer JP (1993) Brain-stem glioma growth patterns. J Neurosurg 78:408-412. https://doi.org/10.3171/jns.1993.78.3. 0408

14. Farmer JP, Montes JL, Freeman CR, Meagher-Villemure K, Bond MC, O'Gorman AM (2001) Brainstem gliomas. A 10-year institutional review. Pediatr Neurosurg 34:206-214. https://doi.org/10. $1159 / 000056021$

15. Forton G, Verlooy J, Cras P, Parizel P, Van de Heyning P (1992) Problems with flute playing: an otological problem? Case report of a peculiar cerebellar astrocytoma. Acta Otorhinolaryngol Belg 46: 405-410

16. Francesco F, Maurizio I, Stefano C, Marina S, Ugo S, Massimo S (2010) Trigeminal nerve root entry zone pilocytic astrocytoma in an adult: a rare case of an extraparenchymal tumor. J Neuro-Oncol 97: 285-290. https://doi.org/10.1007/s11060-009-0020-4

17. Gentry LR, Jacoby CG, Turski PA, Houston LW, Strother CM, Sackett JF (1987) Cerebellopontine angle-petromastoid mass lesions: comparative study of diagnosis with MR imaging and CT. Radiology 162:513-520. https://doi.org/10.1148/radiology.162.2. 3492010

18. Ghodsi M, Mortazavi A, Shahjouei S, Hanaei S, Esmaeili A, Nejat F, El Khashab M (2013) Exophytic glioma of the medulla: presentation, management and outcome. Pediatr Neurosurg 49:195-201. https://doi.org/10.1159/000362621

19. Guillamo JS, Monjour A, Taillandier L, Devaux B, Varlet P, HaieMeder C, Defer GL, Maison P, Mazeron JJ, Cornu P, Delattre JY, Association des Neuro-Oncologues d'Expression Française (ANOCEF) (2001) Brainstem gliomas in adults: prognostic factors and classification. Brain 124:2528-2539. https://doi.org/10.1093/ brain/124.12.2528

20. Hitselberger WE, Gardner G (1968) Other tumors of the cerebellopontine angle. Arch Otolaryngol 88:712-714. https:// doi.org/10.1001/archotol.1968.00770010714020
21. House JL, Burt MR (1985) Primary CNS tumors presenting as cerebellopontine angle tumors. Am J Otol Suppl:147-153

22. Kasantikul V, Palmer JO, Netsky MG, Glasscock ME, Hays JW (1980) Glioma of the acoustic nerve. Arch Otolaryngol 106:456 459. https://doi.org/10.1001/archotol.1980.00790320008003

23. Kasliwal MK, Gupta DK, Mahapatra AK, Sharma MC (2008) Multicentric cerebellopontine angle glioblastoma multiforme. Pediatr Neurosurg 44:224-228. https://doi.org/10.1159/000121380

24. Kawase T, Nakamura T, Kanno T, Nakazato Y (1993) Anaplastic astrocytoma in the cerebellopontine angle. Noshuyo Byori 10:5356

25. Kernohan JW, Woltman HW, Adson AW (1948) Gliomas of the cerebellopontine angle. J Neuropathol Exp Neurol 7:349-367. https://doi.org/10.1097/00005072-194810000-00001

26. Khatib ZA, Heideman RL, Kovnar EH, Langston JA, Sanford RA, Douglas EC, Ochs J, Jenkins JJ, Fairclough DL, Greenwald C (1994) Predominance of pilocytic histology in dorsally exophytic brain stem tumors. Pediatr Neurosurg 20:2-10. https://doi.org/10. $1159 / 000120759$

27. Linsenmann T, Monoranu CM, Westermaier T, Varallyay C, Ernestus R-I, Vince GH (2013) Exophytic glioblastoma arising from the cerebellum: case report and critical review of the literature. J Neurol Surg A Cent Eur Neurosurg 74:262-264. https://doi.org/ 10.1055/s-0032-1304218

28. Mabray MC, Glastonbury CM, Mamlouk MD, Punch GE, Solomon DA, Cha S (2015) Direct cranial nerve involvement by gliomas: case series and review of the literature. AJNR Am J Neuroradiol 36:1349-1354. https://doi.org/10.3174/ajnr.A4287

29. Matsuda M, Onuma K, Satomi K, Nakai K, Yamamoto T, Matsumura A (2014) Exophytic cerebellar glioblastoma in the cerebellopontine angle: case report and review of the literature. J Neurol Surg Rep 75:e67-e72. https://doi.org/10.1055/s-00331364167

30. Mirone G, Schiabello L, Chibbaro S, Bouazza S, George B (2009) Pediatric primary pilocytic astrocytoma of the cerebellopontine angle: a case report. Childs Nerv Syst 25:247-251. https://doi.org/10. 1007/s00381-008-0690-9

31. Ozawa Y, Katsumata Y, Maehara T (1993) Exophytic pontine glioma mimicking acoustic neurinoma: CT and MRI appearance. Radiat Med 11:217-219

32. Panse (1904) Ein Gliom des Akustikus. Arch Ohr Heilk 61:251255

33. Ree A, Jain R, Rock J, Rosenblum M, Patel SC (2005) Direct infiltration of brainstem glioma along the cranial nerves. J Neuroimaging 15:197-199. https://doi.org/10.1177/ 1051228405274534

34. Reifenberger G, Boström J, Bettag M, Bock WJ, Wechsler W, Kepes JJ (1996) Primary glioblastoma multiforme of the oculomotor nerve. Case report. J Neurosurg 84:1062-1066. https://doi.org/ 10.3171/jns. 1996.84.6.1062

35. Revilla AG (1948) Differential diagnosis of tumors at the cerebellopontine angle. Bull Johns Hopkins Hosp 83:187-212

36. Salunke P, Sura S, Tewari MK, Gupta K, Khandelwal NK (2012) An exophytic brain stem glioblastoma in an elderly presenting as a cerebellopontine angle syndrome. Br J Neurosurg 26:96-98. https://doi.org/10.3109/02688697.2011.585670

37. Schneider F, Kompis M, Ozdoba C, Beck J, Caversaccio M, Senn P (2015) Pilocytic astrocytoma of the cerebellopontine angle in a child presenting with auditory neuropathy spectrum disorder. Otol Neurotol 36:e101-e103. https://doi.org/10.1097/MAO. 0000000000000355

38. Selvapandian S, Rajshekhar V, Chandy MJ (1999) Brainstem glioma: comparative study of clinico-radiological presentation, pathology and outcome in children and adults. Acta Neurochir 141:721726; discussion 726-727. https://doi.org/10.1007/s007010050367 
39. Skinner HA (1931) Some histological features of cranial nerves. Arch Neurol Psych 25:356-372

40. Takada Y, Ohno K, Tamaki M, Hirakawa K (1999) Cerebellopontine angle pilocytic astrocytoma mimicking acoustic schwannoma. Neuroradiology 41:949-950. https://doi.org/10. $1007 / \mathrm{s} 002340050874$

41. Tarlov IM (1937) Structure of the nerve root. Arch Neurol Psych 37:1338-1355

42. Teo C, Siu TL (2008) Radical resection of focal brainstem gliomas: is it worth doing? Childs Nerv Syst 24:1307-1314. https://doi.org/ 10.1007/s00381-008-0647-z

43. Theeler BJ, Ellezam B, Sadighi ZS, Mehta V, Tran MD, Adesina AM, Bruner JM, Puduvalli VK (2014) Adult pilocytic astrocytomas: clinical features and molecular analysis. Neuro-oncology 16 : 841-847. https://doi.org/10.1093/neuonc/not246

44. Tomita T, Grahovac G (2015) Cerebellopontine angle tumors in infants and children. Childs Nerv Syst 31:1739-1750. https://doi. org/10.1007/s00381-015-2747-x

45. Wu B, Liu W, Zhu H, Feng H, Liu J (2011) Primary glioblastoma of the cerebellopontine angle in adults. J Neurosurg 114:1288-1293. https://doi.org/10.3171/2010.12.JNS10912
46. Yamamoto M, Fukushima T, Sakamoto S, Tsugu H, Nagasaka S, Hirakawa K, Utsunomiya H, Tomonaga M (1997) Cerebellar gliomas with exophytic growth-three case reports. Neurol Med Chir (Tokyo) 37:411-415. https://doi.org/10.2176/nmc.37.411

47. Yang D-X, Jing Y, Xu Z-M, Yuan F, Liu Y-L, Wang G-S, Tian H-L (2019) Primary glioblastoma of cerebellopontine angle in adult mimicking acoustic neuroma. World Neurosurg 122:48-52. https://doi.org/10.1016/j.wneu.2018.10.073

48. Yousry I, Muacevic A, Olteanu-Nerbe V, Naidich TP, Yousry TA (2004) Exophytic pilocytic astrocytoma of the brain stem in an adult with encasement of the caudal cranial nerve complex (IX-XII): presurgical anatomical neuroimaging using MRI. Eur Radiol 14: 1169-1173. https://doi.org/10.1007/s00330-003-2210-3

49. Zúccaro G, Sosa F (2007) Cerebellopontine angle lesions in children. Childs Nerv Syst 23:177-183. https://doi.org/10.1007/ s00381-006-0208-2

Publisher's note Springer Nature remains neutral with regard to jurisdictional claims in published maps and institutional affiliations. 